\title{
İntegral Hacim Problemleri Çözüm Süreçlerinin Bireysel İlişkiler Bağlamında İncelenmesi; Disk, Pul ve Kabuk Yöntemleri *
}

\begin{abstract}
Ali DELICCE*
Özkan ERGENE ${ }^{* * *}$

Öz

Problem çözme becerilerinin kazanılmasını sağlayan, bireyin dış dünya ile olan bağlantısını farklı gözle görmesine aracılık eden matematik eğitimi, eğitim-öğretim süreci boyunca üzerinde düşünülmesi gerekilen özel bir alandır. Dinamik bir şekilde ilerleme gösteren eğitim-öğretim sürecinde çalışmalar sonucunda uygulama topluluğu gibi kavramlar ortaya çıkmıştır. Ortak kaygı, ilgi, problemleri paylaşan ya da bir konu hakkında süreç boyunca bilgileri geliştiren ve bu alanlarda uzmanlaşma olanağı sağlayan bireylerin bulunduğu öğrenme ortamı olarak tanımlanan uygulama topluluğu kavramı birey, kurum ve karşılıklı ilişki boyutları üzerine temellendirilmiştir. Bu araştırmada üniversite öğrencilerinin integral hacim problemi çözüm sürecindeki disk, pul ve kabuk yöntemlerinin seçimleri uygulama topluluğu temelli bireysel ilişkiler bağlamında incelenmiştir. Araştırma sürecinde çalışma grubunu, İstanbul ilinin bir devlet üniversitesinde olasılıksız örneklem yöntemiyle mühendislik fakültesi, fen edebiyat fakültesi matematik bölümü ve eğitim fakültesi ilköğretim matematik eğitimi bölümünden seçilen 101 öğrenci oluşturmaktadır. Çalışma grubuna geçerliği ve güvenirliği test edilmiş 7 sorudan oluşan İntegral Hacim Testi uygulanmış, bununla birlikte her bir fakülteden rastgele seçilen ikişer öğrenci ile görüşmeler yapılmış ve ilgili derse ait ders defterleri ve ders içerikleri incelenmiştir. Nitel veriler kodlama yöntemiyle analiz edilmiş, betimsel olarak sunulmuştur. Araştırma bulguları üniversite öğrencilerinin performanslarının düşük olduğunu göstermiş olup, çözüm becerileri, sınavlar, kavram imgeleri, görsel beceriler çözüm sürecinde ilişkileri sıcak tutan faktörler olarak bulunmuştur. Ayrıca konu ve kavramdan kaynaklanan ve bireye göre değişme gösterebilen gerekçelerin kurum çerçevesinde farklılaşması, integral hacim problemi çözüm sürecindeki disk, pul ve kabuk yöntem tercihlerinin farklı olmasına neden olmuştur. Bu bağlamda gerek öğrenciden, gerekse dersi anlatan öğretim üyesi ve öğrenme ortamından kaynaklanan kurumsal farklılıkların problem çözüm sürecindeki bireysel ilişkileri etkilediği görülmüştür.
\end{abstract}

Anahtar Kelimeler: Matematik Eğitimi, İntegral Hacim Problemi, Uygulama Topluluğu, Bireysel İlişki.

\footnotetext{
* ERPA International Congresses on Education 2014 (6-8 Haziran 2014/İstanbul-Türkiye) kongresinde sunulan bu çalışma Marmara Üniversitesi Bilimsel Araştırma Projeleri Birimi tarafından desteklenen EGT-C-YLP-280214-0054 projesinden elde edilmiştir.

** Marmara Üniversitesi, Eğitim Fakültesi, Kadıköy /İstanbul/ Türkiye, alidelice@marmara.edu.tr

${ }^{* * *}$ Marmara Üniversitesi, Eğitim Fakültesi, Kadıköy /İstanbul/ Türkiye, ozkanergene@gmail.com
} 


\title{
Investigation of Solving Process in Integral Volume Problems within Personal Relationship; Disk, Washer and Shell Methods
}

\begin{abstract}
Mathematics education that enables individuals to obtain problem solving skills and to see the outer world from a different perspective is a special area that needs to be considered during education-instruction process. As a result of the studies in education and instruction that make progress vigorously, concepts such as communities of practices have emerged. The concept of communities of practices that are described as the learning environment where the individuals who share common concerns, interests and problem or who develop information on a subject in the process and who provide specializiation in these subjects stay on are based on the dimensions of individual, institution and mutual relationship. In this research, university students' preferences of disk, washer and shell methods in the solution process of integral volume problems were scrutinized in terms of personal relationships based on communities of practices. The study group of the research consists of 101 students who are in a state university in İstanbul and chosen by using non-probability sampling method and who are from the faculty of engineering, mathematics department of faculty of science and letters, primary mathematics teaching department of faculty of education. Integral Volume Test, which consists of 7 questions whose reliability and validity were tested, was applied to the study group. Besides, two students chosen randomly from each faculty were interviewed and the course notebooks related to that course and their contents were scrutinized. The data were analyzed and interpreted through coding method and descriptive statistical techniques. As a result of the research, it was discovered that the performances of the university students are low and that factors such as solution skills, tests, concepts images and visualaziation skills affect solution process. The differentiation of the reasons that arise from subject and concept and that may be change according to the individual within the institution have caused different disk, washer and shell methods' preferences in the solution process of integral volume problems. Within this context, it has been discovered that institutional differences emerged from learning environment and adacemic member and students have affected personal relationships in the solution process of the problem.
\end{abstract}

Keywords: Mathematics Education, Integral Volume Problem, Communities of Practices, Personal Relationship.

\section{GİRIŞ}

Öğrenmenin etkin bir şekilde gerçekleşmesi için yapılan çalışmalar ile teknoloji destekli eğitim (Ersoy, 2005; Hembree, \& Desart, 1986), uygulama topluluğu (Goos \& Bennison, 2008; Gomez \& Rico, 2007; Secada \& Adajian; 1997) gibi çeşitli kavramlar ortaya çıkmıştır. Kavramların ortaya çıkış sürecinde yaklaşımlar, ihtiyaçlar ve teoriler etkili olmuştur. Yapılandırmacı paradigma altında incelenen, öğrenmeyi farklı bir bakış açısı ile ilişkilendiren durumlu öğrenme teorisine göre bilgi durumludur ve içinde bulunduğu ortamın, kültürün, çevrenin, uygulamanın bir parçasıdır (Karaman, Özen \& Yıldırım, 2007; Kılıç, 2004). Bilginin günlük hayatta işlevselliğini arttıran durumlu öğrenme, çoğu zaman öğrenmenin gerçekleşeceği aktiviteler ile bilginin topluluk içerisinde işbirlikli yapılanmasını sağlarken bazı durumlarda da tam olarak açık olmayan bilginin netleşmesini sağlar (Herrington \& Oliver, 1995). Bilginin aktarıldığı öğrenme ortamı, bireysel öğrenmenin gelişmesini desteklemenin yanında gerçek bir uygulama topluluğudur ve süreç esnasındaki amaç öğrenme ortamının bu topluluklara dönüştürülmesidir (Ergene, 2014, sf. 12). Bu bağlamda matematik sınıfı genel itibari ile matematik üzerine araştırmalar yapan matematikçiler grubu olarak uygulama topluluğu gibi düşünülebilir (Banks, 2001). Durumlu öğrenmenin uygulanması esnasında bir takım zorluklarla karşılaşıldığından alternatif yaklaşım sergileyen öğrenme teorileri ortaya atılmıştır. Bunlardan bir tanesi de sosyal öğrenme teorisidir. 
Durumlu öğrenme teorisi ile kıyaslandığında öğrenmenin oluşumunu inceleyen, farklı bakış açılarına sahip öğrenme teorilerinden olan sosyal öğrenme teorisi, katılımclların aidiyet duygusu ile bir grupta yer alarak kendi kimliklerini oluşturduğu, belli uygulamaların yapıldığı, bunların sonucunda tecrübeleri bağlamında çevresini anlamlandırmaya çalıştığı, sosyal katılıma dayalı öğrenme sürecini vurgulamaktadır (Wenger, 2008). Bu teori bireysel eylemleri sağlamlaştırmayı ve geçerli kılmayı amaçlayan katılım aracılığı ile bilinçaltı öğrenme sürecinin önemini belirtmektedir (Erkoç, 2012).

Uygulama topluluğu kavramının, öğrenmeye farklı bakış açıları ile yaklaşan sosyal öğrenme teoremi ya da durumlu öğrenme teoreminin iletişiminden çıktığına dair literatürde çeşitli görüşler yer almaktadır. Tight (2004), sosyal öğrenme sisteminin temel taşı olan uygulama topluluğunun sosyal öğrenme teoremi içerisinde tartışmalardan türetildiğini ifade etmiştir. Wenger (2000), Lave ve Wenger (1991) ise bireysel ya da sosyal kurum üzerine temellendirilen öğrenmeyi uygulama topluluğu kavramına dayandırarak açıklamakta ve bununla birlikte durumlu öğrenme çalışmasında yer alan uygulama topluğu kavramını zaman içerisinde gelişen bireyler, alıştırmalar ve yeryüzü arasındaki ilişkiler sistemi olarak tanımlamaktadır. Wenger (2008), daha sonrasinda uygulama topluluğunu bir konu hakkında süreç boyunca bilgileri geliştiren ve bu alanlarda uzmanlaşma olanağ sağlayan, ortak kaygı, ilgi ve problemleri paylaşan bireylerin bulunduğu ve öğrenme ortamı olarak tanımlamıştır.

Uygulama topluluğu her ne kadar eğitim dünyasında yeni bir terminoloji olarak karşımıza çıksa da aslında günlük hayatımızda, içerimizde kısacası gözlerimizin önünde var olan fakat belki de bu kadar anlamlandıramadığımız bir olgudur. Çünkü bilgi, katılımcılar ve karşılıklı ilişki boyutlarından temellendirilen uygulama topluluğu, işte, evde, okulda, eğlencelerimizde karşımıza çıkabilir. Bununla birlikte uygulama topluluğu zaman içerisinde kendi hatalarını düzelten dinamik bir süreç olarak oluşum şartlarına bağlı belli bir isimle belirtildiği gibi isimsiz de olabilir. Uygulama topluluğunun gerek bilgi, gerek katılımcılar ve gerekse karş1lıklı ilişki boyutları ile temellendirilmesinde, içerisinde bulundurduğu öğretmen, öğrenci ve ögrenme ortamı ile topluluğun oluşmasına aracilık eden kurumlar çok önemli bir yere sahiptir. Kurumlar bağlamında uygulama temelli kurallara odaklanan teoriksel ilişki ve onun kısıtlanan kuralları, bireylerin kurum içerisinde öğrendiği matematiksel kavramlar ve öğrenim sürecindeki bireyin bireysel ilişkileri ile gelişiminde önemli rol oynadığı ifade edilmektedir (Chevallard, 2002).

Matematiksel kavramların bireylere aktarılmasinda önemli rol oynayan matematik ve matematik eğitimi dersleri öğretmen, öğrenci ve öğrenme ortamından kaynaklanan birçok etmenin yanında çeşitli strateji, yöntem ve teknikler kullanılarak farklı şekiller ile bireylere aktarılmaktadır. Yüksek öğretim kurumlarının mühendislik fakültesi, eğitim fakültesi ve fen edebiyat fakültesi bölümlerinin lisans, yüksek lisans gibi çeşitli kademelerinde öğrencilerin Kalkulus I-II, Genel Matematik I-II ya da Analiz I-II gibi isimlerde aldığ 1 Analiz dersinin önemli bir kısmını limit, türev ve integral konuları oluşturmaktadır (Ergene, 2014, sf. 26). Analiz dersinin öğretimi ve öğrenimindeki çeşitli zorlukların yaşanması (Sevimli \& Delice, 2011; Calvo, 1997) dersin doğası gereği öğrenim ve öğretim sürecinde bireysel ilişkilerin önemli olacağını göstermektedir. Türev ve limit konuları ile yakından ilişkili olan integral kavramının anlaşılmasındaki güçlük, birçok araştırmacı tarafından ortaya çıkarılmıştır (Sevimli \& Delice, 2011; Rasslan \& Tall, 2002). Çözüm esnasında bireylerin cebirsel, uzamsal ve hem cebirsel 
hem uzamsal becerilerini kullandığı integral konusuna belirsiz ve belirli integral olarak iki kısımda yaklaşılabilir. Belirli integralin uygulaması olarak da gösterilen ve yüksek öğretim kurumları analiz dersleri ders içerikler incelendiğinde farklı alt başlıklar altında yer alan integralde hacim konusu dönel cisimler ile ilgili hacim hesaplamalarını içerir. Bir doğru, ya da eğrinin birleşmesi sonucu oluşan bölgenin koordinat eksenleri ya da bir doğru etrafında döndürülmesi sonucu oluşan dönel cismin hacminin hesaplanabilmesi için "disk", "pul" ve "kabuk" gibi yöntemlerin kullanılması gerekmektedir (Thomas, Weir, Hass \& Giordano, 2009).

Günlük hayatta karşımıza çıkan bir sorun, aşılması gereken engel olarak ifade edebileceğimiz problemi Lester (1983), birey ya da grup için hali hazırda ulaşılabilir bir çözüm yolu olmayan fakat bu çözümün bulunması için ihtiyaç, istek ve çaba zorunluluğunun hissedildiği bir durum olarak tanımlamaktadır. Problem çözme ise bu durumun oluşum sürecinde ortaya çıkmaktadır. Bununla birlikte Schoenfeld (1992) problem çözme teriminin yıllar boyunca çok yönlü ve karşıt görüşlerde içeren bir anlama sahip olduğunu vurgulamıştır. Problem çözme programlarda (NCTM, 2000), matematik kapsamında beceri olarak ifade edilirken, eğitimciler tarafından hem fen hem de matematik için ortak beceri olarak ifade edilmektedir. (Kıray \& İlik, 2011; Kilpatrick, 2010; Venville, Wallace, Rennie \& Malone, 2002). Problem çözme en genel haliyle verilenlerin ve istenenlerin olduğu bir yapı olarak düşünülmektedir. Fakat bu noktada önemli olan verilen ve istenenler arasında farklı yöntemlerin olduğu, farklı durumlar ile döngüsel sürecin karşılıklı devam ettiğidir. Bireylerden asıl beklenen verilenler ve istenenleri yorumlaması ve bireysel paradigmaları ışığında problemi anlamaları ve işlemler yapmasıdır.
$\mathrm{Bu}$ araştırmanın odağı, üniversite öğrencilerinin integral hacim problemi çözüm sürecinde kullandıkları disk, pul ve kabuk yöntemlerinin üniversite öğrencilerinin problemle olan bireysel ilişkileri bağlamında incelenmesidir, ilgili alan yazın incelendiğinde uygulama topluluğu ve bireysel ilişki kavramlarının yer aldığ ${ }^{\prime}$ araştırmaların az olduğu görüldüğünden bu çalışmanın literatüre katkıda bulunacağı düşünülmektedir, bu bağlamda aşağıda yer alan araştırma sorularına cevap aranacaktır;

1. Üniversite öğrencilerinin integral hacim problem çözüm performansları uygulama topluluğu bağlamında nasıl etkilenmektedir?

2. İntegral hacim problem çözüm sürecinde üniversite öğrencilerinin problemle olan bireysel ilişkilerinin, disk, pul ve kabuk yöntemlerine yansımaları nasıldır?

\section{YÖNTEM}

Bilimsel araştırma sürecinde çoğu zaman araştırma yöntem ve tekniğinden önce belirlenmesi gerekliliği olan paradigma bir çok araştırmacı tarafından göz ardı edilen, genel anlamıyla kabul görmüş kurallar bütünüdür (Guba \& Lincoln, 1994). Araştırma paradigmasının ön koşul gibi olduğunu düşünerek seçilecek araştırma sürecine doğrudan etki eden ve araştırmanın nasıl ilerleyeceği hakkında yol gösteren araştırma yöntemi, araştırma odağı doğrultusunda belirlenen araştırma sorularına nereden bakılması gerektiğini ifade eder. Bu nedenle, üniversite öğrencilerinin integral hacim problemi çözüm sürecinde kullandıkları disk, pul ve kabuk yöntemlerinin üniversite öğrencilerinin problemle olan bireysel ilişkileri bağlamında incelenmesini odağına koyan bu araştırmanın pozitivist olmayan yorumlayıcı paradigma (Cohen, Monion \& Marrison, 2000) ile yürütüleceği ifade edilebilir. Araştırmanın paradigması doğrultusunda, çoklu durum çalışması 
araştırma deseni olarak belirlenmiştir. Bu desen, araştırmacının zaman içerisinde sınırlandırılmış bir veya birkaç durumu çoklu kaynakları içeren veri toplama araçları (gözlemler, görüşmeler, görsel-işitseller, dokümanlar, raporlar) ile derinlemesine incelediği, durumların ve duruma bağlı temaların tanımlandığg nitel bir araştırma yaklaşımıdır (Creswell, 2007; Yin, 1994). Araştırmada verilerin detaylı analizinin yapılabilmesi için, yazılanlar, çizilenler ya da gösterilenlerin arka planının belirlenmesi amacryla bilgi toplama çeşitlemesine gidilmiştir. Bu çalışmada da üniversite öğrencilerinin integral hacim problemleri çözüm sürecindeki yöntem tercihleri ve performanslarının uygulama topluluğu bağlamında nasıl etkilediği bütüncül bir yaklaşımla derinlemesine incelenmek istenmektedir.

\section{1 Çalışma Grubu}

Nitel araştırmalarda incelenen ya da araştırılan konu bağlamında birey ve bireyin özellikleri önem kazanmaktadır. Bu çalışmada araştırma odağı doğrultusunda çoklu durum çalışmasının doğasına uygun olarak bireyler ya da olayların olduğu gibi alındığı olasılıksız örneklem seçiminin amaçlı örnekleme tekniği (Patton, 1990) kullanılarak, İstanbul ilinin bir devlet üniversitesinde Analiz derslerini alan üç farklı fakültesinden seçilen 101 öğrenci ile yürütülmüştür. Ayrıca üniversite öğrencilerinin problem çözüm süreçlerindeki yöntem tercihleri gibi durumların arkasında yatan nedenleri incelemek amaciyla her bir fakülteden rastgele seçilen ikişer öğrenci ile görüşmeler yapılmıştır. Mühendislik fakültesi (MF) öğrencileri, (servis dersini alan çevre mühendisliği, inşaat mühendisliği, makine mühendisliği bölümleri öğrencilerinden oluşmuştur), fen edebiyat fakültesi matematik bölümü (MB) öğrencileri ve eğitim fakültesi ilköğretim matematik eğitimi (IME) öğrencilerinin tamamı gerek ders adı gerekse konu adı farklı olmasına rağmen Ana- liz dersleri ders içerikleri incelendiğinde integralde hacim konusunu işlemişlerdir.

\subsection{Veri Toplama Araçları}

Üniversite öğrencilerinin problem çözüm yöntemlerine etki eden kişiler arası bireysel ilişkilerin belirlenmesi için araştırmacı tarafından hazırlanmış İntegral Hacim Testi (IHT) kullanılmıştır. Test hazırlama süreci esnasında yüksek öğrenim kurumlarının Analiz dersi ders içerikleri ve integralde hacim konusunu içeren kaynaklar incelenerek integralde hacim konusu kapsaminda yer alan bireylerin problem çözme sürecinde problemle olan ilişkilerini açığa çıkartmak amaciyla 25 tane problem oluşturulmuştur. Oluşturulan IHT taslak formu, integral konusu hakkında çeşitli çalışmalar yapmış 3 farklı uzmana araştırma amacı, odağı ve problemlerinin detaylı olarak anlatılarak incelenmesi sağlanmıştır. Uzman görüşleri sonrasında belirtilen hedefleri sağlamadığı gerekçesiyle 14 problem testten çıkartılmış ve analiz dersi integralde hacim konusunu gören 9 kişilik gruba pilot uygulama yapılmıştır. Uygulama sonrası problem çözüm süreçlerinin analizleri yapıldıktan sonra 4 problem testten çıkartılmış ve 7 problemlik IHT tekrardan uzmanlara gösterilmiştir. Uzmanların tamamı tarafından görüş birliğine varılan İHT uygulama esnasında kullanılmışır. Araştırma kapsamında kullanılan İHT, matematik eğitimi alanında yüksek lisans yapmış 3, doktora yapmış 2 uzman tarafından değerlendirilmiş ve görünüş geçerliğini sağladığı ifade edilmiştir. Ayrıca test hazırlama sürecinde üniversitelerin ders içeriklerinde yer alan integralde hacim konusuna ait alt başlıklar incelenmesi ve matematik eğitimi alanında uzman 3 kişi tarafından kontrol edilmesi testin kapsam geçerliğini sağladığını gösteren kanıtlardır. Testte yer alan sorular kolay, orta ve zor olarak zorluk düzeyleri, ders içi etkinlikler, ödev ya da sınavda sorma amaçlı kullanılma tercihleri ve çözüm yöntemi özellikleri bak1- 
mından 5 farklı uzman tarafından değerlendirilmiştir. Uzman görüşleri sonrasında \%85 tutarlılık göstermesi testin problem özelliklerine göre kodlayıcı güvenirliğini sağladığını göstermiştir.

Araştırma sürecinde elde edilen verilerin detaylı bir şekilde analiz edilebilmesi için öğrencilerin testlere verdikleri cevapların ders içerisindeki yaşanmışlıklarının etkisi olup olmadığı ve ders sürecinde öğretim üyesinin problem çözüm sürecinin etkisini incelemek amacıyla her bir fakülteden rastgele seçilmiş 2 farklı öğrenci ile yarı yapılandırılmış görüşme yapılmıştır. Yarı yapılandırılmış görüşme için hazırlanan görüşme formu 3 farklı uzmana araştırma odağı ve araştırma problemleri hakkında bilgi verildikten sonra verilmiş ve uzmanlar tarafından görüş birliğine varılmıştır. Ayrıca ders esnasındaki anlatılan konu ve çözülen problemlere ait inceleme yapmak, öğrencilerin uygulama sonrası problem çözüm süreçleri ve yapılan görüşmelerin analizinde ders içi etkileri belirlemek üzere üç farklı bölümün ilgili ders defterleri ve öğretim üyesi tarafından önerilen kaynak kitap incelenerek doküman analizi yapılmıştır.

\subsection{Verilerin Analizi}

Nitel veri analizinde uygulanan stratejiler, teknik ve süreçler düşünüldüğünde alan yazında ortak bir dilin geliştiğinden söz edebilmek mümkün değildir (Özdemir, 2011; Bogdan \& Biklen, 1998). Nitel araştırmalarda farklı ortamlara ve gruplara uygulanabilen önceden belirlenmiş kesin kurallar ve standart yaklaşımlar olmadığı için, her araştırma problemi kendine özgü bir araştırma deseni ve veri analiz stratejisini gerektirdiği düşünülmelidir (Yıld1rım \& Şimşek 2013). Bu araştırmada üniversite öğrencilerinin İHT'ne verdiği cevaplar araştırma problemlerine cevap bulabilmek amaciyla betimsel istatistik kullanılarak analiz edilmiştir (Robson, 1993, sf. 385-390).
Uygulama sonrasinda İHT'ne verilen cevaplar öncelikle araştırmacı tarafından hazırlanmış bir tablo ile Doğru Cevap (DC), Yanlış Cevap (YC), Kısmi Cevap (KC) ve Boş Cevap (BC) olarak değerlendirilmiştir. Problemlerin değerlendirilmesi için kullanılan tablonun doğrultusunda güvenirliği sağlamak için araştırmacı tarafından rastgele seçilen 25 kağıt, üç farklı uzmana verilmiş ve değerlendirilmesi istenmiştir. Değerlendirme sonrasında araştırmacılar da dâhil olmak üzere verilen cevaplar incelendiğinde \%95 oranında örtüşme olduğu gözlemlenmiştir.

Üniversite öğrencilerinin problem çözümünde kullandıkları çözüm yöntemlerinin incelenmesi için İHT'ne verilen cevaplar, problem çözüm sürecindeki seçilen yöntemler ve problem çözme performansı bağlamında bölüm bazında analiz edilmiştir. Problem çözüm süreçlerinde karşılaşılan çözüm yöntemleri disk, pul, kabuk ile diğer/boş (geometrik ve çözüm yapılmama durumunu içeren) olmak üzere dört kategori altında toplanmıştır. Yöntem seçimlerinin ve problem çözüm süreçlerinin arkasında yatan nedenleri ve bu seçimlere etki eden durumların belirlenmesi için yapılan görüşmeler araştırma problemleri doğrultusunda detaylı olarak analiz edilmiştir. Ayrıca problem çözüm yöntemlerine ve süreçlerine dersi anlatan öğretim üyesinin etkisini belirlemek amaciyla ders defterleri ve kaynak kitaplar incelenmiştir.

\section{BULGULAR}

İHT'ne ait bulgular, soru kâğıtlarına verilen cevaplar ve cevapların arka planında yer alan doğrudan gözlemlenemeyen durumların belirlenmesi için yapılan görüşme ve doküman analizine ait sonuçlar üç alt başlık halinde sunulacaktır. Öncelikle İHT'ne verilen cevaplar neticesinde birey performanslarına ait bulgular verilecek, sonrasında integral hacim problemi çözüm sürecindeki disk, pul ve kabuk yöntemlerinin kullanılması ve bu yöntemlere ilişkin 
hatalara ait bulgular verilecek en sonunda ise ders defterleri ve ders içeriklerinin incelenmesine ait bulgular verilecektir.

\section{1 Integral Hacim Testi Birey Performansları}

Üniversite öğrencilerin İHT'ne verdikleri cevapların DC, YC, KC ve BC olarak değerlendirilmesi sonucu genel ve bölüm bazlı oluşan performansların yüzdeleri Tablo 1'de verilmiştir. Üniversite öğrencilerinin tamamının İHT'ne verdiği DC ve KC'ların çok düşük olduğu ayr1ca öğrencilerin neredeyse yarısının sorulara cevap veremediği gözlemlenmiştir (Tablo 1). Verilen cevaplar bölüm bazlı incelendiğinde, MB öğrencilerin çok büyük çoğunluğunun sorulara cevap veremediği bunun yanında sorulara en fazla doğru cevabı verenlerin MF öğrencilerinin olduğu tespit edilmiştir. Testte yer alan sorulara verilen cevaplar incelendiğinde, birinci, ikinci ve üçüncü sorulara verilen doğru cevapların sayısının fazla olduğu fakat beşinci ve yedinci soruya adayların büyük çoğunluğunun doğru cevap veremediği gözlemlenmiştir.

Tablo 1. Üniversite Öğrencilerinin İntegral Hacim Testi Performansları Yüzdelik Tablosu

\begin{tabular}{ccccc}
\hline Bölüm & DC & YC & KC & BC \\
\hline MF & 19,5 & 27,1 & 13,8 & 39,6 \\
MB & 7,6 & 16,8 & 12,4 & 63,2 \\
IME & 13,8 & 25,8 & 14,2 & 46,2 \\
Genel & 13,6 & 23,2 & 13,5 & 49,7 \\
\hline
\end{tabular}

\section{2 İntegralde Hacim Problemleri Çözüm Sürecinde Kullanılan Yöntemler}

Üniversite öğrencilerinin integral hacim problemleri çözüm süreçlerindeki disk, pul ve kabuk yöntemleri kullanma ve bu yöntemlerin haricinde geometrik yöntemlerin kullanılması ve karşılaşılan durumlar iki alt başlık halinde verilmiştir.

Disk, pul ve kabuk yöntemleri: İntegral hacim problemlerinin çözümünde dik, pul ve kabuk yöntemlerinin yanı sıra geometrik yöntemlerin ve yöntemlere ilişkin formül ve işlemsel yapıların kullanıldığı görülmüştür.
Matematikten faydalanirım. Formüller kullanılyor, formüllerden yararlanırm. Yöntemler kullanilyyor. Disk yöntemi, pul yöntemi, kabuk yöntemi, onlardan faydalanirm.

Kullanılan disk, pul ve kabuk yöntemlerinin kullanım sıklıklarının bireylerin ait oldukları bölümlere göre farklılık gösterdiği ve farklı çözüm yöntemlerinin kullanıldığı gözlemlenmiştir (Tablo 2). Üniversite öğrencilerinin İHT problemleri çözüm yöntemleri incelendiğinde, disk yönteminin kabuk yönteminden daha fazla tercih edildiği ve çözüm sürecinde en fazla kullanılan yöntemin pul yöntemi olduğu görülmüştür.

Tablo 2. Üniversite Öğrencilerinin İntegral Hacim Testi Çözüm Yöntemleri Yüzdelik Tablosu

\begin{tabular}{ccccc}
\hline Bölüm & Disk & Pul & Kabuk & Diğer/Boş \\
\hline MF & 17,5 & 33,6 & 1,9 & 47 \\
MB & 2 & 13,3 & 17,4 & 67,3 \\
IME & 8,2 & 39,8 & 0 & 52 \\
Genel & 9,2 & 28,9 & 6,4 & 55,4 \\
\hline
\end{tabular}

İntegral hacim problemleri çözüm sürecinde kabuk yönteminin genellikle MB öğrencileri 
tarafından kullanıldığı gözlemlenirken, IME bölümünde okuyan öğrencilerin kabuk yöntemini hiç kullanmadığı gözlemlenmiştir.

Geometrik çözüm yöntemleri ve yöntem çözümlerinde karşılaşılan durumlar: MF ve MB öğrencilerinden farklı olarak İME öğrencilerinin disk, pul ve kabuk yöntemleri haricinde Tablo 2'de \%52 olarak gösterilen bölümün neredeyse yarıya yakın kısmının katı cisimlerin hacim formüllerini içeren geometrik yöntemleri kullandıkları tespit edilmiştir (Şekil 1).

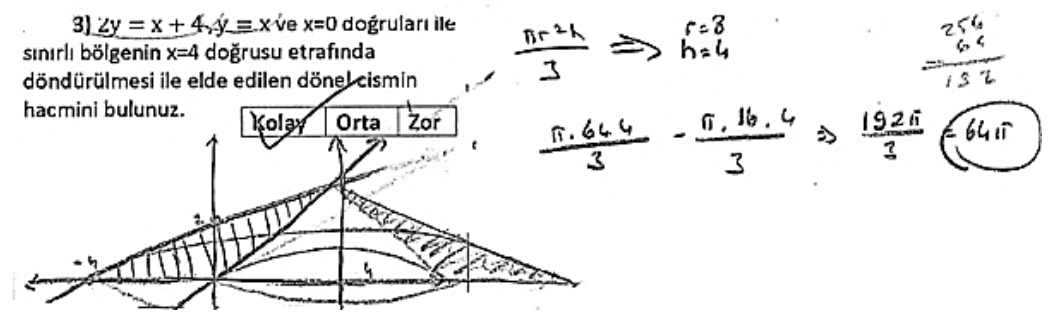

Şekil 1. İntegral Hacim Problemi Çözümünde Geometrik Yöntemin Kullanılmasına Ait Çözüm Örneği

İHT'ni çözen üniversite öğrencilerinin problem çözüm sürecinde kullandıkları disk, pul ve kabuk yöntemlerine ilişkin seçilen yöntemin gerektirdiği formül ve formül içerisinde yer alan bazı ifadelerin kullanılmamasına ait bazı hatalara sahip oldukları belirlenmiştir.

İHT'ni çözen üniversite öğrencilerinin problem çözüm sürecinde kullandıkları disk, pul ve kabuk yöntemlerine ilişkin seçilen yöntemin gerektirdiği formül ve formül içerisinde yer alan bazı ifadelerin kullanılmamasına ait bazı hatalara sahip oldukları belirlenmiştir.

$\ddot{U}_{c ̧}$ tane yöntem kullaniliyor, disk, pul ve kabuk. Bunlara iyi çalıştım. Formülleri, $\pi \int_{x_{1}}^{x_{2}}(f(x))^{2} \quad \pi \int_{x_{1}}^{x_{2}}(f(x)-g(x))^{2}$ $2 \pi \int_{x_{1}}^{x_{2}} x . f(x) d x$.
Üniversite öğrencilerinin formülleri karıştırma ya da hatırlamama durumları ile karşılaşılmış, formül üzerinde düşünmelerini sağlayarak hatalarının farkına varmalarını sağlanmıştır.

$\pi \int_{x_{1}}^{x_{2}}(f(x)-g(x))^{2}$, ilk başta çıkartıp karesini alacağız. Pul yöntemi... Aaa, ben yanlış yapıyor muşum. Sizin testte de tüm soruları yanlış çözdüm. Tabi ya.

Üniversite öğrencileri, yöntem seçimlerinden sonra yönteme ait bilgilerde çeşitli sorunlar yaşamaktadır. Öğrencilerin problem çözüm sürecinde seçtikleri pul yöntemi ile ilgili plan tasarlama aşamasında \%84,8'i yöntemin gerektirdiği çözümü; $\int_{a}^{b} \pi\left[f^{2}(x)-g^{2}(x)\right]$ gerçekleştirirken, geri kalanının ise $\int_{\mathrm{a}}^{\mathrm{b}} \pi\left[(\mathrm{f}(\mathrm{x})-\mathrm{g}(\mathrm{x}))^{2}\right]$ şeklinde gösterilen hatayı yaptıkları (Şekil 2) görülmüştür.

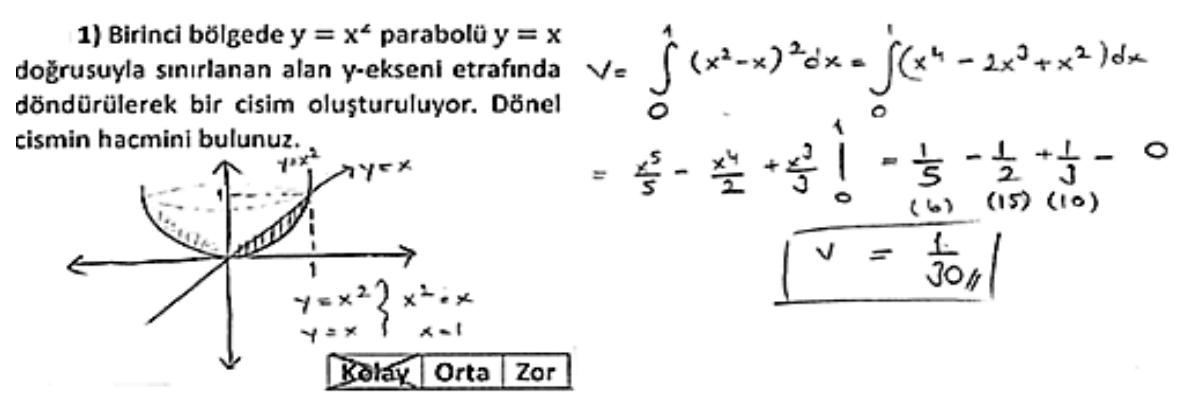

Şekil 2. Pul Yöntemi Kullanılarak Yapılmış Hatalı Çözüm Örneği 
Verilen cevaplar incelendiğinde, İME öğrencilerinin büyük çoğunluğunun integral hacim problemleri çözüm yöntemlerinde bulunan pi katsayısını çözüm sürecine yansıtmadıkları
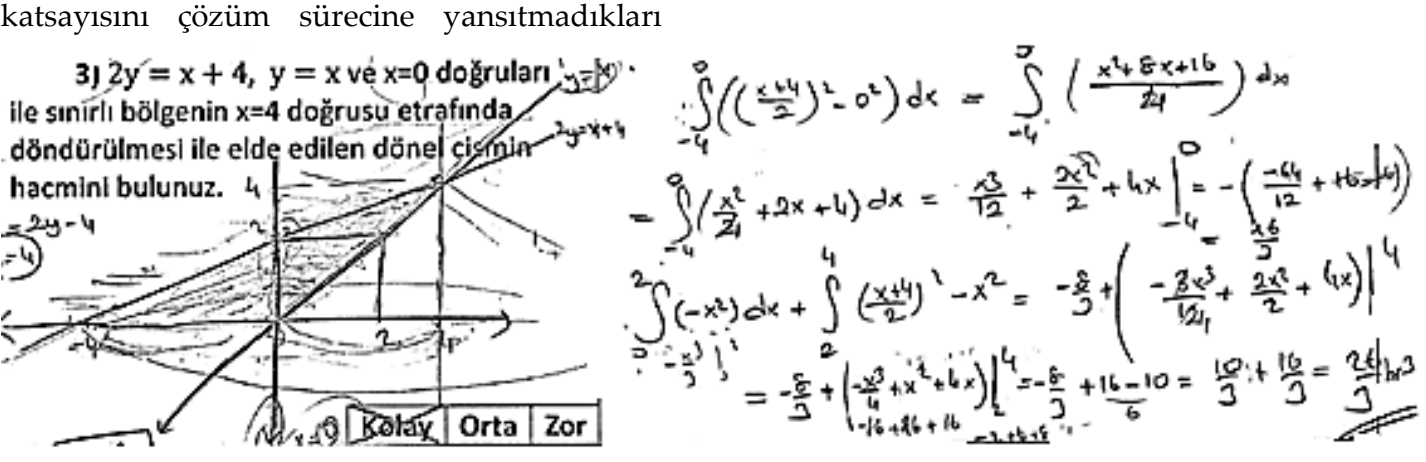

Şekil 3. Pi Katsayısının Kullanılmadan Cevabın Bulunmasına Ait Çözüm Örneği

\subsection{Doküman Analizi}

Bireylerin problem çözüm sürecinde bölüm bazlı benzerlik ve farklılıkları tespit edebilmek için integralde hacim konusuna ait olan ders içerikleri incelenmiştir (Ergene, 2014). İntegralde hacim konusunun sadece MB ders içeriğinde açıkça belirtildiği buna karşın diğer bölüm-
(Şekil 3) buna karşın diğger iki bölümde okuyan öğrencilerde bu duruma çok fazla rastlanmadığ1 gözlemlenmiştir. 
Tablo 4. Bölümlerin Ders Defterlerinin Örnek Sayısı, Ders Saati ve Sayfa Sayısı Bağlamından İncelenmesi

\begin{tabular}{|c|c|c|c|c|}
\hline Fakülte & $\begin{array}{l}\text { Örnek } \\
\text { Sayıs1 } \\
\end{array}$ & $\begin{array}{l}\text { Ders } \\
\text { Saati }^{*}\end{array}$ & $\begin{array}{l}\text { Sayfa } \\
\text { Say1s1 }\end{array}$ & Açıklamalar \\
\hline MF & 12 & $3+3$ & 8 & $\begin{array}{l}\text { Disk ve pul yöntemleri detaylı ola- } \\
\text { rak verilip ilgili yöntemlere ait ör- } \\
\text { nek çözülmüş buna karşın kabuk } \\
\text { yöntemine ait sadece bir örnek } \\
\text { vardır. }\end{array}$ \\
\hline MB & 6 & $3+3$ & 5 & $\begin{array}{l}\text { Kabuk ve pul yöntemi üzerinde } \\
\text { durulmuş bunun yanında disk } \\
\text { yöntemi teorik olarak verilip örnek } \\
\text { çözülmeden pul yöntemine geçil- } \\
\text { miştir. Ayrıca şekil içeren sorular } \\
\text { çok fazla çözülmemiştir. }\end{array}$ \\
\hline İME & 11 & $3+2$ & 7 & $\begin{array}{l}\text { Disk ve pul yöntemine ait bilgiler } \\
\text { teorik olarak verilmiş aynı zamanda } \\
\text { örnekler çözülmüş, kabuk yöntemi } \\
\text { başlık olarak ifade edilmeden örnek } \\
\text { çözülmüştür. }\end{array}$ \\
\hline
\end{tabular}

* Birinci kısım teorik ders saatini, ikinci kısım uygulamalı ders saatini göstermektedir.

Bireylerin problem çözüm sürecinde tercihlerini doğrudan etkileyen ders esnasında anlatılanlar ve yaşanmışlıkların göstergesi olarak ifade edilebilen ders defterlerinin incelenmesi sonrasında, konu anlatım esnasında yöntemler ve onlara ait formüllerin net olarak gösterilmesine rağmen örnek çözümlerde formül ifadelerin net olarak belirtilmemesi, pi katsayısının yer almaması gibi bazı eksiklikleri içeren bölümsel farklılıkların olduğu gözlemlenmiştir (Tablo 4). Ayrıca fakültelerin her birinde integral hacim yöntemleri, disk, pul ve kabuk yöntemi olarak aynı sırada verilmiş fakat süreç esnasında yöntemlere ait örnek sayısı ve konuya ayrılan ders saati düşünüldüğünde farklılıklar oluştuğu gözlemlenmiştir.

\section{Tartışma}

Problemlerin, kendileri, çözüm süreçleri ve sonuçları bir bütün olarak düşünüldüğünde anlam arz ettikleri söylenebilir (Ergene, 2014). $\mathrm{Bu}$ bütünü oluşturan her bir öğeyi problemi çözen üniversite öğrencilerinin sahip oldukları zihinsel, duygusal ve psikomotor becerilerin yanı sıra ait oldukları bölüm odaklı özellikleri ile birleştirip ardından performanslara bakılması gerektiği kâğıt üzerinde yapılanlar ve görüşmelerde söylenenlerden çıkarılmıştır. İntegral hacim problemlerinde üniversite öğrencilerinin performanslarının düşük olması süreçte gösterdikleri bilgi, becerilerin ve fakülte bazlı özelliklerin performanslarına yansıması olarak ifade edilebilir.

Üniversite öğrencileri, çözüm stratejilerinde kullanılabilecek disk, pul ve kabuk yöntemlerine ilişkin yanlış hatırlama ya da karıştırma ya da kullanamama gibi çeşitli zorluklar yaşamışlardır. Bu durum doğası gereği integralde hacim konusunun ve integral alma işleminin zorluğundan (Sevimli, 2009) kaynaklanabileceği gibi (Şekil 4), ders içerisinde öğretim üyesinin pedagojik yaklaşımları ve bunları kendi üzerine yansitan üniversite öğrencilerinin çözüm süreci boyunca sergiledikleri davranışların yansıması sonucunda da kaynaklanabilir.

Çok fazla formülleri hatırlamadım ondan olabilir, bu konu da çok kasıntılı. Birde bazı 
sorularda çok uzun işlemler vardı integral içerisinde, dönüşüm falan yapmak gereki-

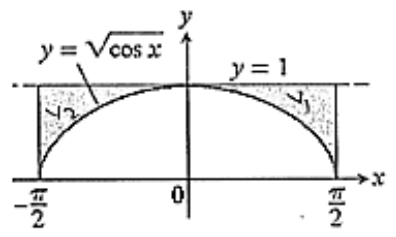

yordu. Onları yapamadım.

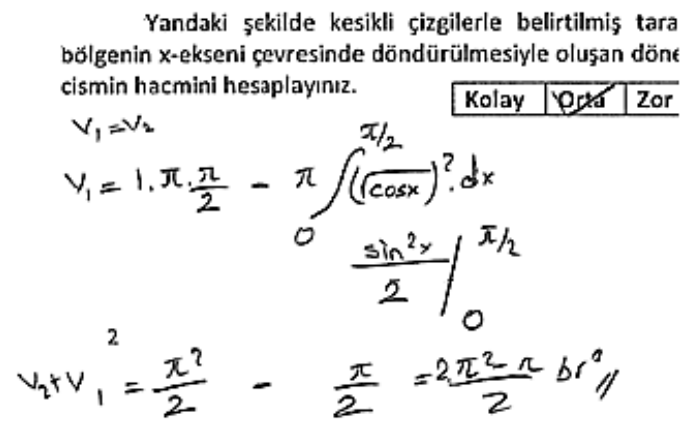

Şekil 4. İntegral Hacim Problemi Çözüm Örneği 1

Performans ve çözüm sürecindeki farklılıkların, fakültelerin amaçlarının (öğretim programlarının) yanı sıra problem çözücülerinin ve dersi anlatan öğretim üyesinin algıları, yaklaşım ve davranışlarının öğrenme ve öğretme süreci üzerindeki etkisinden kaynaklandığı düşünülmektedir (Bingölbali \& Monaghan, 2004). Üniversite öğrencilerinin problem çözme sürecinde gerçekleştirdiği hatırlayamama, uygulayamama ya da yanlış uygulama gibi zihinsel aktiviteleri ve psikomotor becerileri probleme olan bakışlarını etkilemektedir. Problemler birey olarak algılanıp ilişkiler $\mathrm{ku}-$ rulurken, problem çözüm sürecinin de kurulan bu ilişkilerin yönünü belirlediği gözlenmektedir, öyle ki bu durum üniversite öğrencilerinin kullanması gereken yöntemleri ve yönteme ait formülleri çözüm sürecinde pratiğe dökmesinde etkili olabilmektedir.

İsimlerini hattrlamiyorum. Bir tanesinde iki fonksiyonun karesi alınıp çıkartıllyordu, diğerinde ise yarıçap bulunuyordu. Tam olarak hatırlamiyorum. Bu yüzdende hiç sevmedim bu konuyu....

Performansin yüksek olduğu durumlarda ortaya çıkabilen pozitif motivasyonun üniversite öğrencisinin kavramları, çözüm süreçlerini daha iyi yapılandırıp, pekiştirmesine sebep olduğu söylenebilir. Bununla birlikte başarısızlık ya da performansın düşük olduğu durum- larda ise problemleri (ve süreçlerini) karşısında duran ve birey rolü yüklediği tek bir nesne olarak algılayabilir. Başarısız olduğunu düşündüğü problemleri birey olarak algılayan üniversite öğrencisi, çözme süreçlerine bireyin davranışları muamelesi yaparak benzer süreçli problemlerle karşılaştığında bu davranışa sahip bireylerle (yani başarısız olduğu çözüm sürecine götürecek problemlerle) karşılaşmak istemeyebilir, hatta bu tür davranışlara nasıl karşılık vereceğini bilememe karmaşası yaşayabilir. Problemle olan bireysel ilişkiler problem çözüm sürecinde değişkenlik göstererek hem süreci hem de problem çözücüleri etkilemektedir (González-Martín, 2013). Başka bir ifadeyle problem çözücüler problemleri birey ve problem çözüm süreçlerini de bireyin davranışları kabul ederek bireyselleştirebilir bu da onların problemlerle olan ilişkisini etkileyebilir. Buradan genellikle üniversite öğrencilerinin problemle olan bireysel ilişkisi, problem çözme sürecinde çözüm stratejisi, yöntem ve tekniklerini düşünmeksizin üniversite öğrencilerinin zihinsel etkinlikleri ile birlikte duygusal tepkilerinin, motivasyon, yaklaşım ve inançlarının problem çözümü esnasında birleşmesi olarak tanımlanabilir (Ergene \& Delice, 2014). Bununla birlikte süreç esnasında problemle olan bireysel ilişkinin durumuna ve yönüne göre bazen zihinsel aktiviteler duygusal aktivitelere baskın olurken bazen de duygusal aktiviteler çözüm 
sürecinde daha fazla rol alarak zihinsel aktivitelere baskın olabilir (Ergene, 2014). Birey yakıştırması yapılan problemle olan ilişki sosyal (problem çözücü ile bireye benzetilen problem arasındaki muhtemel bağ), psikolojik (problem çözücü) ve matematik (epistemolojik) yönü düşünüldüğünde kolay çağrışım yapması ve sosyal anlamda kullanılan bireylerden (insanlardan) farklılığını ortaya koyması açısından sosyo-psiko-matematik ilişki olarak isimlendirilebilir.

Eğitim öğretim süreci içerisinde üniversitelerce hazırlanan aynı derslere ait fakülte bazlı ders içeriklerinin kısmi değişiklikler haricinde benzerlik gösterdiği düşünüldüğünde fakülte bazlı performans farklılıklarının yanında ders içerisinde yapilan uygulamalarda, formül ya da işlemin gerektirdiği bazı detayların verilmemesi, ders esnasinda yeterince üzerinde durulmaması gibi durumların dersi anlatan öğretim üyesi etkisi ve problem çözücülerinin sahip oldukları bireysel özellikler ile şekillendiği ifade edilebilir. Aynı zamanda ders içerikleri, fakülte ya da fakülteye ait öğretim üyesi ya da öğrenme ortamı gibi kurumsal yansımaların bireysel farklılıklara neden olduğu göz önüne alındığında kurumsal farklılıklar ve bireysel farklılıkların karşlıklı olarak birbirinden etkilendiği ve bu farklılıkların problemle olan bireysel ilişkileri etkilediği söylenebilir (Şekil $5)$.

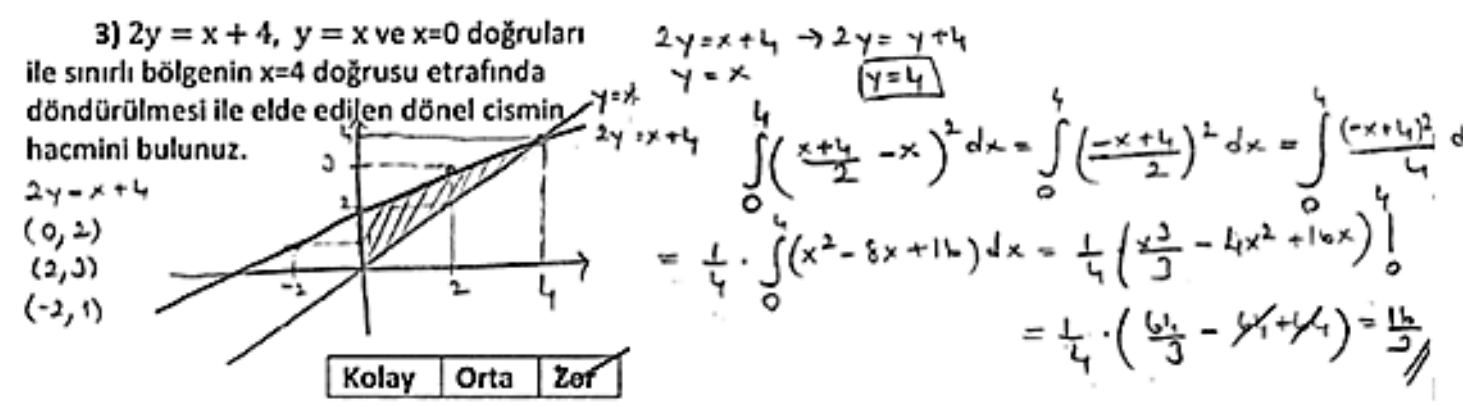

Şekil 5. İntegral Hacim Problemi Çözüm Örneği 2

Üniversite öğrencilerinin neredeyse yarısına yakınının problemleri cevaplayamaması ve problem çözüm süreci sonrası performanslarının çok düşük olması problem çözücü başarısı, ders öğretim üyesi başarısı, kurum başarısı ve sistem başarısını etkileyen önemli faktörler olarak düşünülebilir. Ayrıca fakülteler arasında performans farklılıklarının olması öğrenme ortamlarını etkilediğinden (NCTM, 2000), süreç esnasında kurumsal etkilerin üzerinde durulması gerektiğini gösteren önemli bir durum olarak ifade edilebilir. Bu bağlamda her bir fakültenin özelliğinden kaynaklanan farklılıkların olmasının yanında üniversitelerin ders içeriğinde yer alan konulara ilişkin hedeflenen başarıların gerçekleşmemiş olduğu görülmek- tedir. Üniversite öğrencilerinin belirtilen hedeflere ulaşmamasındaki bir diğer etken olarak da konuların ya da aktarılan ifadelerin sinav odak11 düşünülmesi ve gerçek hayatta kullanılmaması gibi bireysel durumlar örnek olarak verilebilir.

Yani zaten sinavda çıkacak belki ama ben ileride bunları kullanmayacağım için çokta umursamadım açıkçası. Sınavda da diğer sorulara çok bakarmm diye düşündüm.

Tartışmalar bu araştırma için bireysel ilişkilerin performans, problem çözme süreci ve süreçte kullanılacak tekniklerin belirlenmesi, süreçte karşılaşılan her bilişsel yansıma, problem çözücünün kendisi, arkadaşları, sınıfı, öğretmeni, 
kurumu, ders kitabı ve defteri ile şekillendiğini ve somuttan soyuta psikomotordan bilişsel aktivitelere uzandığını göstermektedir.

\section{Sonuç ve Öneriler}

Günlük hayatın her bir noktasında olan uygulama topluluklarının eğitim öğretim süreci içerisinde bilgi, karşılıklı ilişki ve katılımcılar boyutunda olduğu gözlemlenmiştir (Wenger, 2000). İntegral hacim problemleri çözüm sürecinde problem ve çözüme ait kavramlar, öğretim üyeleri tarafından anlatılanlar ve öğrencilerin sahip olduğu bilgi ve beceriler ve yaşanmışlıkların etkileşimi ile oluşan uygulama topluluğu sürecin her bir aşamasında karşımıza çıkmaktadır. Kurum içerisindeki üç fakülteye ait problem çözüm performanslarının farklı olması ve çözümlere ilişkin yöntem, formül kullanımlarının farklı olması, her bir fakültenin benzerliklerinin yanında farklılıklar gösteren değerleri ve özellikleri olduğunu göstermektedir. $\mathrm{Bu}$ bağlamda performans ve çözüm sürecindeki farklılıklar problem çözücüden kaynaklandığ gibi kurumdan da kaynaklamaktadır.

Bir kurumda, bilginin aktarılması, değiştirilmesi ya da içselleştirilmesi esnasında oluşan farklılıkların öğrenmeye olan etkisinin varlığını kabul etmekle birlikte, eğitim öğretim sürecini etkileyen kurumsal ilişkinin (Chevallard, 1998) bilgi boyutu yanında problem çözücünün süreç esnasında yaşadığı her türlü olguyu etkileyen bir etmen olduğunun altı çizilmelidir. Yapılan görüşmeler sonucunda üniversite öğrencileri genellikle yöntemlerin isimlerini hatırlamamış, problem içerisinde yer alan işlemsel ifadelerin gerektirdiği çözüm adımlarını gerçekleştirememiş ve yönteme ait formül yapıları net olarak ifade edememişlerdir. Ayrıca çözüm sürecinde kullanılmayan yöntemler ders esnasında detaylı olarak gösterilmemiş ya da sınav odaklı düşünülerek ders hocaları tarafından tercih edilmemiştir. Problem çözüm sürecinde kurum ilişkisinin üniversite öğrencilerine yansıması ile öğrencilerde oluşan etkenler probleme karşı pekiştireç oluşturmakta bu da üniversite öğrencilerinin problemle olan bireysel ilişkilerini ortaya çıarmaktadır (Ergene, 2014). Problem çözüm sürecindeki bireysel ilişkiler, problemin çözümünü etkilemektedir ki bu bazen öğrenciye avantaj sağlamakta, hedefe ulaşılmasını kolaylaştırmakta iken bazı durumlarda ise dezavantaj oluşturmaktadır.

Öğrenme ortamlarına yeni bakış açısı kazand1ran uygulama toplulukları kavramının, matematik eğitiminde her bir aşama da kullanabilecek bir kavram olduğu düşünülmektedir. Çünkü özellikle integral, türev gibi analiz dersi konularında ortaya çıkan düşük ya da yetersiz birey performansı dolayısıyla grup performansının artırılması için bu bakış açısıyla öğrenme ortamları düzenlenebilir. Ayrıca öğrenme ortamları için önemli bir kavram olarak ifade edilebilecek olan sosyo-psiko-matematik ilişki kavramını temel alan çalışmaların yapılması, problem çözüm süreçlerinin irdelenmesinde, problem çözme performanslarında oluşan farklılıkların açığa çıkartılmasında ve problem çözücünün sürece olan yaklaşımının belirlenerek performansa tesir edecek iyileştirmeler yapılabilmesinde gerekli olduğu düşüncesiyle önerilebilir. Bununla birlikte ayn kurumda farklı fakültelerdeki aynı derslere ait performans, başarı durumları incelenmeli ortaya çıkan farklılıkların nedenleri tespit edilmeli ve istenilen başarı düzeyi için gerek ders anlatımı, gerek ders içeriği düzenlemesi, gerekse konu bütünlüğü ve eğitim ortamı açısından eşit şartlar düşünülmeli bununla birlikte kurumsal farklılıkların etkisi de göz ardı edilmemelidir. 


\section{Kaynakça}

Banks, B. (2001). Learning theory and learning objects Online Erişim. http://myweb.tiscali.co.uk/ adresinden erişilmiştir.

Bingölbali, E. \& Monaghan, J. (2004). Identity, knowledge and departmental practices: mathematics of engineers and mathematicians. 28th International Conference for the Psychology of Mathematics Education (PME), (2),127-134.

Bogdan, R. C. \& Biklen, S. K. (1998). Qualitative research for education: Introduction and methods. Boston: (3rd ed.). Allyn and Bacon.

Calvo, C. (1997). Bases para una propuesta dida'ctica sobre integrales. Tesis de Maestría, Universitat Auto 'noma de Barcelona.

Chevallard, Y. (1998). Analyse des pratiques enseignantes et didactique des mathématiques: L'approche anthropologique. La Rochelle-France.

Chevallard Y. (2002). Organiser l'étude. 1. Structures \& fonctions, Actes de la XI eécoled'été de idactique des mathématiques. La Pensée Sauvage, Grenoble, 3-32.

Cohen, L., Manion, L. \& Morrisson, K. (2000). Research methods in education (5th Ed.). London: Routlenge Falmer.

Creswell, J. W. (2007). Qualitative inquiry research design: Choosing among five approaches. (Second ed.) Thousand Oaks, California: Sage Publications.

Delice, A. \& Sevimli, E. (2011). İntegral kavramının öğretiminde konu sıralamasının kavram imgeleri bağlamında incelenmesi; belirli ve belirsiz integraller. Pamukkale Üniversitesi Eğitim Fakültesi Dergisi. 30(1), 51-62.

Ergene, Ö. (2014). İntegral hacim problemleri çözüm sürecindeki bireysel ilişkilerin uygulama topluluğu bağlamında incelenmesi (Basılmamış Yüksek Lisans Tezi). Marmara Üniversitesi.

Ergene, Ö. \& Delice, A. (2014). İntegral hacim problemleri çözüm sürecinde kullanılan $\quad$ yöntemlerin incelenmesi. Sözlü Bildiri. ERPA Congress, İstanbul, (6-8 Haziran).

Erkoç, S. (2012). Uygulama topluluğu olarak sınıflar: iletişim ağına sahip ortamda öğrenmeyi planlama ve kolaylaştırma. Sakarya University Journal of Education, 2(3). 116-135.

Ersoy, Y. (2005). Matematik eğitimini yenileme yönünde ileri hareketler-I: Teknoloji desteklimatematik öğretimi TOJET: The Turkish On Line Journal of Educational Technology. 4-2/7.

Go'mez, P. \& Rico, L. (2007). Learning Within Communities of practice in preservice secondary school teachers education. PNA, 2(1), 17-28.

González-Martín, A.S. (2013a). Students' personal relationship with series of real numbers as a consequence of teaching practices. Proceedings of the 8th Congress of the European Society for Research in Mathematics Education(CERME8). Antalya (Türkiye).

Goos, M. E. \& Bennison J. A. (2008). Developing a communal identity as beginning teachers of mathematics: Emergence of an online community of practice. Math. Teacher Education, 11,41-60.

Guba, E. G. \& Lincoln, Y. S. (1994). Competing paradigms in qualitative research. In N.Denzin ve Y. Lincoln (Eds.), Handbook of qualitative research, Sag Publications.

Hembree R. \& D. Dessart. (1986). Effects of hand-held calculators in precollege mathematic education: A meta-analaysis. Journal for Research in Mathematics Education, 17, 83-89.

Herrington, J. \& Oliver, R. (1995). Critical characteristics of situated learning: Implications for the instructional design of multimedia. Ed: J. Pearce, A. Ellis. Learning with technology, 235-262. 
Karaman, S., Özen, Ü. \& Yıldırım, S. (2007). Öğrenme nesnelerinin pedagojik boyutu ve öğrenme ortamlarına kaynaştırılması. Eğitim ve Bilim Dergisi, 32(145), 3-15.

Kılıç, E. (2004). Durumlu öğrenme kuramının eğitimdeki yeri ve önemi. GÜ, Gazi Ĕ̆itim Fakültesi Dergisi, 24(3),307-320.

Kıray S.A. \& İlik A. (2011). Polya'nın problem çözme yönteminin fen bilgisi öğretiminde kullanılmasına yönelik bir çalışma: Kanıt temelli uygulamaya doğru. Selçuk Üniversitesi Ahmet Keleşoğlu Eğgitim Fakültesi Dergisi, 31,183-202.

Kilpatrick, J. (2010). Research on problem solving in mathematics. School Science and Mathematics. 78(3), 189-192.

Lave, J. \& Wenger, E. (1991). Situated learning: Legitimate peripheral participation. Cambridge: Cambridge University Press.

Lester, F. K. (1983). Trends and issues in mathematical problem-solving research. In R. Lesh \& M. Landau (Eds). Acquisition of mathematics concepts and processes. New York: Academic Press

National Council Of Teachers Of Mathematics, (2000). Principles and standards for school mathematics (Reston, VA: National Council of Teachers of Mathematics).

Özdemir, M. (2011). Nitel Veri Analizi: Sosyal Bilimlerde Yöntembilim Sorunsalı Üzerine Bir Çalışma. Eskişehir Osmangazi Üniversitesi Sosyal Bilimler Dergisi, 11(1).

Patton, M. Q. (1990). How to use qualitative methods in evaluation. London: Sagem Publications, 80-87.

Rasslan, S. \& Tall, D. (2002). Definitions and images for the definite integral concept. In Cockburn A., Nardi, E. (eds.) Proceedings of the 26th PME, 4, 89-96.

Robson, C. (1993). Real world research: a resource for social scientists and practitioners researchers, (1st edition). Oxford: Blackwell, 385-390.

Schoenfeld, A. H. (1992). Learning to think mathematically: Problem solving, metacognition, and sense making in mathematics. In D. Grows (Ed), Handbook of research on mathematics teaching and learning (pp. 334-370). New York: MAcmillan.

Secada, W. G. \& Adajian, L. B. (1997). Mathematics teachers' change in the context of their professional communities. In L. Fennema \& B. S. Nelson (Eds.), Mathematics teachers in transition (pp. 193-219). Mahwah, NJ: Lawrence Erlbaum Associates.

Sevimli, E. (2009). Matematiköğretmen adaylarmm belirli integral konusundaki temsil tercihlerinin uzamsal yetenek ve akademik başarı bağlamında incelenmesi. Yüksek Lisans Tezi. İstanbul.

Tight, M. (2004). Research into higher education: an a-theoritical community of practice. Higher Education Research \& Development. 23(4), 395-411.

Thomas, Jr. G. B., Weir, M.D., Hass, J. \& Giordano, F. R. (2009). Thomas' calculus, 12th Edition. Pearson.

Venville, G. J., Wallace, J., Rennie, L. J. \& Malone, J. A. (2002). Curriculum integration: Eroding the high ground of science as a school subject? Studies in Science Education, 17, 43-84.

Wenger, E. (2000). Communities of practice and social learning systems. Organization, 7, 225- 246.

Wenger, E. (2008). Communities of practice: learning, meaning, and identity, Cambridge University Press, New York. 17.

Yıldırım, A. \& Şimsek, H. (2013). Sosyal bilimlerde nitel araştırma yöntemleri, (6. Baskı). Seçkin Yayıncllık. Ankara.

Yin, R. (1994). Case study research: Design and methods, Second Thousand Oaks, CA: Sage. 


\section{Extended Summary}

Mathematics education that enables individuals to obtain problem solving skills and to see the outer world from a different perspective is a special area that needs to be considered during educationinstruction process. The situated learning theory and the social learning theory which suggest different ideas on learning lead to the emergence of some concepts related to learning, such as community of practices. Communities of practices, which enhance information related to a topic during the process or share the common worries, interests and problem and offer the possibility of agreement, are based on the idea of individuals, institutions and their mutual relationship (Wenger, 2008, Ergene, 2014). Given the higher education instutions, Analysis which name is Analysis I-II, General Mathematics I-II or Calculus I-II, is formed big part of limit, derivative and integral (Ergene, 2014, pp. 26,). In this research, university students' preferences of disk, washer and shell methods in the solution process of integral volume problems were scrutinized in terms of personal relationships based on communities of practices. Sub-questions are determined as follows.

How is university students' performance of integral volume problems solving processes effected by communities of practices?

How is university students' personal relationship with problem in problem solving processes reflected on solving methods (disk, washer and shell)?

In accordance with focus and questions, this study uses a non-positivist paradigm (Cohen, Monion \& Marrison, 2000). This study uses qualitative research in terms of data. Purposive sampling, a category of non-probabilistic sampling technique, was used for the selection of the individuals (Patton, 1990). In this context, the participants this study is knew Volume of Integral, 101 students who registered in engineering faculty (EF), science faculty department of mathematics (MD), education faculty primariy education mathematics teaching (PMT) program offered by a public universtiy in İstanbul, Turkey. The data collection instruments were Integral Volume Test (IVT), semi structered interviews and document analysis, which were used according to the nature of the problem and to the expectations of the researchers.

Using expert opinions, pilot scheme and results from the validity-reliability analyses, IVT was developed. The test consists of seven questions each of related with integral volume problems solving methods which are disk, washer and shell. Textbooks, course content, curriculum and relevant literature were taken into account to determine 25 questions which then were reduced to seven according to the predetermined objectives. The test was found to have face and content validity, intercoder and interrater reliability after the analyses based on the experts in the area and some applications related with nature of test (Also expert opinions are accepted sufficient for the validity and the reliability of the test). After administering the test, and semi-structured interviews were conducted with six respondents who selected two students each departments for deeper understanding of their solution processes and methods preferences. Document analyses have done for determining differences in practise and instutional choises.

To analyze the data, first, in order to determine the levels of achieving the answers were assessed using the labels including correct answer (CA), partially answer (PA), incorrect answer (IA) and no attempt (NA). Second, problem solving process was examined within institutions in terms of integral volume 
test solving methods which are disk, washer and shell. Findings of interwiew and document analyses were analyzed from the point of performance, method preferencess and instutional differences.

Findings has seperated three parts which are IVT findings, interwiew findings and document analyses findings. Students have seen low solving performances during IVT and about half of them don't answer questions (Table I). Considering CA performances, MD is the lowest and EF is the best. All of the departments' IA performances more than CA performances and PA performances.

Table I: Percentage Table of Integral Volume Test Performances

\begin{tabular}{ccccc}
\hline Department & CA & IA & PA & NA \\
\hline EF & 19,5 & 27,1 & 13,8 & 39,6 \\
MD & 7,6 & 16,8 & 12,4 & 63,2 \\
PMT & 13,8 & 25,8 & 14,2 & 46,2 \\
Total & 13,6 & 23,2 & 13,5 & 49,7 \\
\hline
\end{tabular}

Seeing that Table II, washer method the most preferred and shell method is at least. Disk method is preferred EF the most. Contrary to not used by PMT students, shell method is used MD students the most.

Table II: Integral Volume Test Solving Methods Percentage Table

\begin{tabular}{ccccc}
\hline Department & Disk & Washer & Shell & $\begin{array}{c}\text { Alternative/No } \\
\text { Attempt }\end{array}$ \\
\hline EF & 17,5 & 33,6 & 1,9 & 47 \\
MD & 2 & 13,3 & 17,4 & 67,3 \\
PMT & 8,2 & 39,8 & 0 & 52 \\
Total & 9,2 & 28,9 & 6,4 & 55,4 \\
\hline
\end{tabular}

Beside disk, washer and shell method, some students used geometry formulas of solid like cone volume $\left(\pi r^{2} h / 3\right)$ (Figure I). Although students different choises about IVT solving methods, they encounter with same situations which are forgetting, unable to remember, lack of learning or misconception.

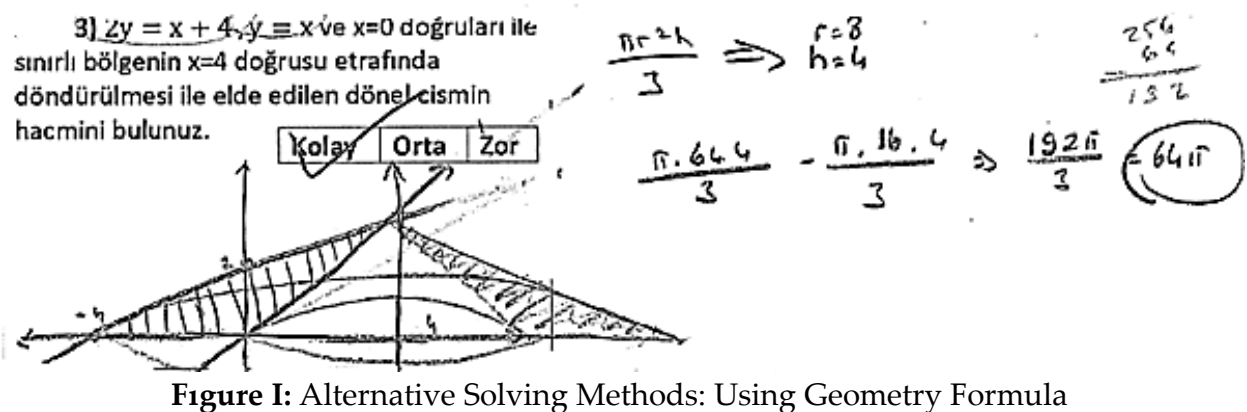

When interwiew and document analyses examined, method preferences and concept usages take shape with lesson experiences and exam anxiety etc. Findings from the analyses of books of lessons and lecture notes revealed that there were a lot of questions about IVT solving methods but some lecture solved 
problems about methods two or three maximum. This might be differences on performance and preferences.

It has been concluded from the interview and papers that problems themselves, solution processes and their results should be thought as a whole and that performances should be taken into consideration after combining every element forming the whole with department focused features as well as cognitive, emotional and psycomotor skills that individuals solving problems have. As performance differences among faculties affect learning environments (NCTM, 2000), organizational effects can be described as an essential situation to be emphasized during the process.

It has been observed that the communities of practices, which is a part of daily life, is in the dimensions of information, mutual relationship and particiants in the education and instruction process (Wegner, 2000). This approach which is based on communities of practices and which gives a new point of view should be used in order to increase low and insufficient performance and to increase group performance accordingly in every step of mathematics education, especially in the courses of analysis such as integral and derivative and it is thought that it is a concept that can be applied in the process. 